\title{
COVID-19 pneumonia treated with ultra-low doses of radiotherapy (ULTRA-COVID study): a single institution report of two cases
}

\author{
Elena Moreno-Olmedo ${ }^{1}$ Vladimir Suárez-Gironzini ${ }^{1} \cdot$ Manuel Pérez $^{2} \cdot$ Teresa Filigheddu $^{2} \cdot$ Cristina Mínguez $^{3}$. \\ Alba Sanjuan-Sanjuan ${ }^{4}$ José A. González ${ }^{5}$. Daniel Rivas ${ }^{6} \cdot$ Luis Gorospe $^{7}$ - Luis Larrea ${ }^{8}$ Escarlata López ${ }^{1}$
}

Received: 22 July 2020 / Accepted: 31 December 2020 / Published online: 27 January 2021

(c) Springer-Verlag GmbH, DE part of Springer Nature 2021

\begin{abstract}
Introduction Since the outbreak of coronavirus disease 2019 (COVID-19) pandemic, healthcare systems have focused their efforts into finding a treatment to avoid the fatal outcomes of severe acute respiratory syndrome due to coronavirus-2 (SARS-CoV-2). Benefits and risks of systemic treatments remain unclear, with multiple clinical trials still ongoing. Radiotherapy could play a role in reducing the inflammatory response in the lungs and relieve life-threatening symptoms.

Methods We designed a prospective study of Ultra-Low Doses of Therapy with Radiation Applied to COVID-19 (ULTRA-COVID) for patients who suffer pneumonia, are not candidates for invasive mechanical ventilation and show no improvement with medical therapy.

Results We present the preliminary results of two patients diagnosed with COVID-19 pneumonia treated with ULTRA-COVID. After one radiotherapy session, significant clinical response and a good radiological response was observed in both cases, resulting in both patients being discharged from hospital in less than 2 weeks after radiation treatment.

Conclusion Preliminary clinical and radiological results suggest a potential benefit of treating COVID-19 pneumonia with ULTRA-COVID.

ClinicalTrials.gov Identifier: NCT04394182
\end{abstract}

Keywords COVID-19 pneumonitis $\cdot$ SARS-CoV-2 $\cdot$ Radiation $\cdot$ Cytokine storm $\cdot$ Inflamatory response

Elena Moreno-Olmedo, M.D.

escarlata.lopez@genesiscare.es

1 Department of Radiation Oncology, La Milagrosa Hospital, GenesisCare, Madrid, Spain

2 Department of Internal Medicine, La Milagrosa Hospital, Madrid, Spain

3 Department of Radiophysics, La Milagrosa Hospital, GenesisCare, Madrid, Spain

4 Oral and Maxillofacial Surgeon, Universtiy Hospital Reina Sofía, Córdoba, Spain

5 Department of Radiation Oncology, GenesisCare, Seville, Spain

6 Department of Radiation Oncology, GenesisCare, Málaga, Spain

7 Department of Radiodiagnosis, La Milagrosa Hospital, Madrid, Spain

8 Department of Radiation Oncology, Vithas Valencia Consuelo Hospital, Valencia, Spain

\section{Introduction}

The onslaught of coronavirus disease 2019 (COVID-19) has challenged healthcare infrastructures worldwide. In this evolving situation and with still many unanswered questions about the optimal therapeutic approach, healthcare systems worldwide have struggled with a rise of critically ill patients [1].

Although the majority of COVID-19 patients are asymptomatic, complications such as severe pneumonia, respiratory failure, or acute respiratory distress syndrome (ARDS) can occur, often leading to fatal outcomes for patients. Most of the time, these cases require intensive care unit (ICU) admission and invasive mechanical ventilator (IMV) support [2].

In the case of these critically ill patients, the host response against the virus appears to be mediated by a 'cytokine storm or release syndrome (CRS)', leading to a macrophage-mediated inflammatory mechanism (inflammatory M1-phenotype) [3] and ARDS, in the form of 
bilateral pneumonitis. In order to prevent patient progression to the critical state, it has been proposed that the CRS can be safely treated with a single course of ultra-low dose of radiotherapy (ultra-LDRT) < 1 Gy [2, 4] which could alleviate symptoms of respiratory distress quickly, helping to reduce mortality without significant long-term sequelae [5].

As Confucius said: "Study the past if you would define the future" and indeed the past may hold the key answer to support the application of ultra-low dose of radiotherapy for these patients. The use of a single ultra-LDRT to treat pneumonia was reported in the early 1900s in 15 studies, involving 863 patients. It showed $80-85 \%$ rates of inflammatory relief success and an overall mortality reduction from $30 \%$ to $10 \%$ [6]. The established role of radiotherapy in nonmalignant inflammatory conditions [7] due to its antiinflammatory properties such as decreasing levels of proinflammatory cells including cytokines and macrophages (polarizing them toward an anti-inflammatory M2-like phenotype) has been practically explored in our study [8-10].

We have hypothesized that ultra-LDRT applied to COVID-19 patients (ULTRA-COVID) could play a role in reducing the pulmonary inflammatory response, counteracting the CRS, reducing the risk of requiring IMV and relieving life-threatening symptoms [4].

Given the need to rapidly communicate information on the global clinical effort against COVID-19, we would like to share this report that describes patient eligibility criteria, treatment course parameters and clinical outcomes of our first two patients with COVID-19 pneumonia treated with ultra-LDRT.

\section{Methods}

After approval by a local ethics committee, a prospective study was designed and initiated at La Milagrosa Hospital (Madrid, Spain) to treat COVID-19 patients with ultraLDRT.

The main purpose of the study was to establish the efficacy of LDRT, as an anti-inflammatory treatment in patients with COVID-19 pneumonia and with a poor response to medical treatment who would otherwise be eligible for IMV, but because of other comorbidities they were not ICU candidates. Given the extremely unusual clinical situation and poor disease prognosis if left untreated, the study has been designed without a control arm.

We identified eligible patients after reviewing their medical records for their biographical data and medical history. The Charlson Comorbidity Index (CCI; $>$ or $<6$ score) [11] was then calculated for each patient. The diagnosis of COVID-19 was proven by polymerase chain reaction (PCR) on nasal and oral swabs and a blood gas analysis was used to calculate the $\mathrm{Pa} 02 / \mathrm{Fi} 02$ ratio ( $>$ or $<300 \mathrm{~mm} \mathrm{Hg}$ ). We measured the oxygen saturation status $(>$ or $<93 \%)$ and the ventilatory support with oxygen therapy (from nasal cannula $[\mathrm{NC}]$, increasing to Ventimask [VMK], and finally VMK with reservoir). In addition, blood analysis was done for inflammatory and immunological parameters, including total lymphocyte count, IL-6 levels, D-dimer, ferritin and lactate dehydrogenase (LDH) levels, C-reactive protein (CRP) and fibrinogen [12, 13].

All patients underwent a baseline thoracic computerized tomography (CT) scan, which was used to evaluate lung involvement using the Total Severity Score (TSS) [14]. This score ranged from 0 to 20 according to the sum of the percentage of involvement of each of the 5 lung lobes, which were scored from 0 to 4 points. The same senior thoracic radiologist estimated the lung involvement as mild (TSS 0-5), moderate (TSS 6-15), or severe (TSS $>15$ ). Patients with worsening TSS score during admission of $>5$ were considered eligible for the ultra-LDRT study.

Those patients should have a baseline performance status $\leq 3$ on the Eastern Cooperative Oncology Group (ECOG) scale [15] and a life expectancy of $>1$ month at the time of hospital admission for COVID-19 pneumonia. Patients who had previous thoracic radiotherapy and/or chemotherapy history were also included in the study. All patients provided assigned written consent, stating that they understood the purpose of the treatment and the risk that such treatment may not work.

\section{Treatment protocol}

Ultra-LDRT was administered using 6 MV photon beams through a Tomotherapy Hi-Art Accuray ${ }^{\circledR}$ (Accuray, Madison, WI, USA) linear accelerator and following institutional safety procedures. A clean patient access circuit from ward to the radiotherapy unit and back was established and both patients were treated last on the day. The treatment protocol team included: 1 radiation oncologist, 1 internal medicine doctor, 1 radiation physicist, 3 radiographers and 1 cleaning staff member. All of them were provided with appropriate personal protective equipment (PPE PSH $310 \mathrm{Bio}^{\circledR}$ ) to reflect the high-risk exposure. The two patients were transferred through one specific internal hospital elevator. In order to reduce staff exposure in the radiotherapy unit, a fasttrack process was designed including simulation, contouring, dosimetry and treatment in one go.

The simulation images were acquired by megavoltage CT (MVCT) in the Tomotherapy ${ }^{\circledR}$. Immobilization was done in supine position with thorax board and with arms support $\mathrm{SIHO}^{\circledR}$. Three radiopaque marks were placed on the patient skin. The contouring was made in Pinnacle ${ }^{3}$ v.9.10 Philips ${ }^{\circledR}$ (Philips Radiation Oncology Systems, Fitchburg, WI, USA) station and dosimetry in Tomotherapy Hi-Art 
Planning Station 5.1.1.6 Accuray ${ }^{\circledR}$ (Accuray, Madison, WI, USA). The planning target volume (PTV) was defined as both whole lungs extended $1 \mathrm{~cm}$ isotropically. No dose constraints were applied to surrounding organs. Regarding the target coverage, the $90 \%$ of PTV should receive $100 \%$ of the prescription dose and the maximum hotspots dose should be $<110 \%$.

Verification imaging was carried out using a MVCT limited to the central third of the thorax, to correct for any error. Total single dose administered was $0.8 \mathrm{~Gy}$ in a $3 \mathrm{~min}$ session.

At the end of treatment and in order to guarantee asepsis the next oncological day, a complete surface decontamination was performed using locally established decontamination procedures.

\section{Response evaluation}

The radiological response was assessed using TSS change on CT imaging, which was evaluated in two separate occasions, 7 days and 4 weeks after the treatment finished. Radiological improvement was defined as mild (TSS decrease $<3$ points), moderate (TSS decrease $3-5$ points), or high (TSS decrease $>5$ points) from the baseline CT.
The clinical response was evaluated by repeat pulseoximetry, blood gas analysis and lab analysis as above, at days 2, 5, 7, and at 4 weeks after ultra-LDRT. Two months later, oxygen levels and pulse-oximetry were evaluated again. A Sp02 $>93 \%$, a reduction of oxygen therapy support, a $\mathrm{Pa} 02 / \mathrm{FiO} 2>300 \mathrm{~mm} \mathrm{Hg}$ and the achievement of normal range value in one or more of the inflammatory and immunological parameters on blood analysis, was considered as clinical improvement.

Radiotherapy toxicity was assessed using the Common Terminology Criteria for Adverse Events (CTCAE v5.0) scale [16].

\section{Case reports}

After establishing our protocol, 4 patients with COVID-19 pneumonia were candidates for ultra-LDRT. One refused to participate and another died before receiving the treatment. The other two participants met the study inclusion criteria and are discussed below.

Patients' clinical characteristics are summarized in Table 1 .

Table 1 Patients' characteristics

\begin{tabular}{|c|c|c|}
\hline Variables & Patient 1 & Patient 2 \\
\hline Gender & Male & Female \\
\hline Ethnic & South-American & Caucasian \\
\hline Age & 80 & 65 \\
\hline Smoking history & No & No \\
\hline Medical history & $\begin{array}{l}\text { Hypertension } \\
\text { Right lower limb amputation due to myxofibrosarcoma in } \\
\text { remission }\end{array}$ & $\begin{array}{l}\text { Asthma } \\
\text { Lumbar stenosis } \\
\text { Uterine polypectomy }\end{array}$ \\
\hline $\mathrm{CCI}$ & 2 & 2 \\
\hline $\begin{array}{l}\text { Previous thoracic } \\
\text { RT }\end{array}$ & No & No \\
\hline $\begin{array}{l}\text { Chemotherapy his- } \\
\text { tory }\end{array}$ & No & No \\
\hline $\begin{array}{l}\text { Onset symptoms } \\
\text { date }\end{array}$ & 12 April 2020 & 12 March 2020 \\
\hline $\begin{array}{l}\text { Admitted hospital } \\
\text { date }\end{array}$ & 15 April 2020 & 19 March 2020 \\
\hline Onset symptoms & Dyspnea, cough, mild fever and chest pain & Dry cough, fever, asthenia and dysgeusia \\
\hline ECOG at admission & 3 & 2 \\
\hline Temperature $\left({ }^{\circ} \mathrm{C}\right)$ & 37.5 & 38.5 \\
\hline $\mathrm{BP}(\mathrm{mmHg})$ & $153 / 80$ & $120 / 70$ \\
\hline Heart rate $(\mathrm{bpm})$ & 92 & 100 \\
\hline Oxygen saturation & $70 \%$ & $87 \%$ \\
\hline Cardiac auscultation & Rhythm without murmurs & Tachycardia heart rhythm without murmurs \\
\hline $\begin{array}{l}\text { Pulmonary ausculta- } \\
\text { tion }\end{array}$ & Crackles predominantly in bilateral lower $2 / 3$ & $\begin{array}{l}\text { Decrease in vesicular murmur. } \\
\text { Crackles predominantly bibasal and left }\end{array}$ \\
\hline
\end{tabular}

CCI Charlson Comorbidity Index, ECOG Eastern Cooperative Oncology Group, ${ }^{\circ} \mathrm{C}$ degrees Celsius, $\mathrm{BP}$ Blood Pressure, $\mathrm{mm} \mathrm{Hg}$ millimeters of mercury, bpm beats per minute 

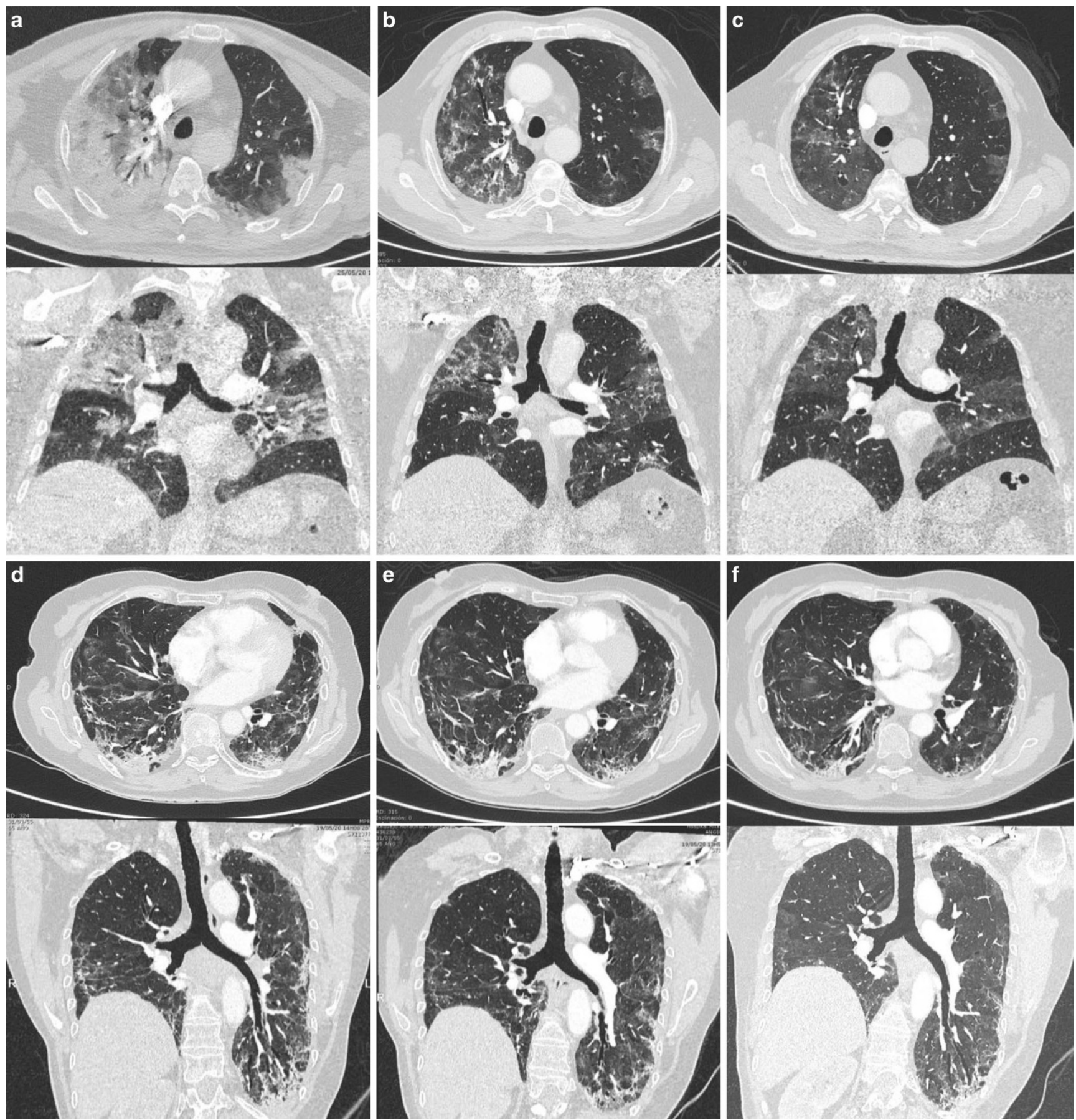

Fig. 1 CT scan evaluation. Axial and coronal reconstructions of computed tomography (CT) scans for patient 1: a Baseline, $\mathbf{b}$ first follow-up 7 days after radiotherapy (RT), $\mathbf{c}$ second follow-up at month 1. Patient 2: d Baseline, e first follow-up 7 days after RT, f second follow-up at month 1

\section{Patient 1}

An 80-year-old man presented to the emergency department with a 3-day history of dyspnea, cough and chest pain. He showed 70\% Sp02 and tachypnea. Pulmonary auscultation revealed crackles on lower two-thirds of both lungs. During hospitalization the patient needed increasing ventilatory support (50\% reservoir, $15 \mathrm{~L}$ of flow) and $\mathrm{SpO} 2$ was around $87 \%$ at best. The baseline CT thorax showed bilateral pneumonia and extensive bilateral ground-glass opacities corresponding to an acute inflammatory stage and ARDS (Fig. 1a). 


\section{Patient 2}

A 65-year-old woman presented to the emergency department with persistent cough, fever, asthenia and dysgeusia, leading to her being admitted. During hospitalization, radiological studies showed pneumomediastinum, making her ineligible for IMV. After 5 weeks of admission and several desaturation episodes, her respiratory status evolved and she needed support with VMK 40\%. The CT scan ruled out the possibility of pulmonary embolism and showed moderate bilateral pneumonia, bronchiectasis, and subpleural bands suggesting an advanced inflammation phase (Fig. 1d).

The medical therapy administrated to both patients consisted of lopinavir/ritonavir (Kaletra ${ }^{\circledR}$ ) 100/400 mg/12 h for 7 days after admission; hydroxychloroquine (Dolquine
${ }^{\circledR} 200 \mathrm{mg} / 12 \mathrm{~h}$ ), azithromycin $500 \mathrm{mg} / 24 \mathrm{~h}$ for 3 days; piperazillin/tazobactam $4 \mathrm{~g} / 0.5 \mathrm{~g}$ administered every $6 \mathrm{~h}$ for 5 days in patient 1 and for 14 days in patient 2 (neither patient required readjustment due to impaired kidney function), prophylactic doses of low-molecular-weight heparins (Enoxaparin $40 \mathrm{mg} / 24 \mathrm{~h}$ ), corticosteroids (methylprednisolone-Urbason ${ }^{\circledR}-250 \mathrm{mg} \times 3$ boluses) and tocilizumab (600 mg single dose). Despite this pharmacotherapy, prone position and oxygen support, the respiratory status and high inflammatory parameters of both patients continued to worsen. At this point, their enrollment in the ULTRACOVID study was decided and a single ultra-LDRT was administered in both patients on April 23, 2020.

Table 2 Results

\begin{tabular}{llllllllll} 
Patient 1 & \multicolumn{1}{l}{ Patient 2 } \\
\cline { 1 - 1 } $\begin{array}{l}\text { Pre-RT } \\
\text { (Baseline) }\end{array}$ & Day 2 & Day 5 & Day 7 & Month 1 & $\begin{array}{l}\text { Pre-RT } \\
\text { (Baseline) }\end{array}$ & Day 2 & Day 5 & Day 7 & Month 1
\end{tabular}

\begin{tabular}{|c|c|c|c|c|c|c|c|c|c|c|}
\hline \multicolumn{11}{|l|}{ Blood test } \\
\hline $\begin{array}{l}\text { D-Dimer } \\
(\mathrm{mg} / \mathrm{dl})\end{array}$ & 4.11 & 1.7 & 1.13 & 0.80 & 0.27 & 1 & 0.44 & 0.42 & 0.41 & 0.30 \\
\hline IL-6 (pg/ml) & 112.2 & 67.1 & 40.1 & 39.8 & 7.76 & 46 & 20 & 12.1 & 6.2 & 4.19 \\
\hline $\mathrm{Hb}(\mathrm{g} / \mathrm{dl})$ & 15.8 & 15.0 & 15.6 & 15.9 & 15.0 & 12 & 10.7 & 9.9 & 9.9 & 12.9 \\
\hline $\mathrm{CRP}(\mathrm{mg} / \mathrm{dl})$ & 0.4 & 0.10 & 0.00 & 0.10 & 0.14 & 1 & 0.10 & 0.30 & 0.10 & 0.02 \\
\hline Ferritin (ng/ml) & 747 & 685 & 721 & 775 & 367 & 916 & 647 & 545 & 469 & 185 \\
\hline $\begin{array}{l}\text { Lymphocytes } \\
\text { (cells/ } \mu \text { and \%) }\end{array}$ & $\begin{array}{l}760 \\
(8 \%)\end{array}$ & $\begin{array}{l}750 \\
(14 \%)\end{array}$ & $\begin{array}{l}760 \\
(14.4 \%)\end{array}$ & $\begin{array}{l}670 \\
(13.7 \%)\end{array}$ & $\begin{array}{l}1509 \\
(30 \%)\end{array}$ & $\begin{array}{l}740 \\
(27.5 \%)\end{array}$ & $\begin{array}{l}1310 \\
(30.5 \%)\end{array}$ & $\begin{array}{l}760 \\
(22.6 \%)\end{array}$ & $\begin{array}{l}1100 \\
(24.6 \%)\end{array}$ & $\begin{array}{l}700 \\
(6.6 \%)\end{array}$ \\
\hline LDH (UI/l) & 457 & 350 & 341 & 346 & 396 & 727 & 567 & 607 & 523 & 672 \\
\hline $\begin{array}{l}\text { Fibrinogen } \\
(\mathrm{mg} / \mathrm{dl})\end{array}$ & 598 & 443 & 458 & 395 & 325 & 492.00 & 516 & 419 & 557 & 260 \\
\hline \multicolumn{11}{|c|}{ Radiological assessment (CT scan) } \\
\hline CT TSS & 16 & & & 11 & 9 & 10 & & & 9 & 7 \\
\hline RUL TSS & 4 & & & 3 & 3 & 1 & & & 1 & 1 \\
\hline RML TSS & 3 & & & 2 & 2 & 1 & & & 1 & 1 \\
\hline RLL TSS & 3 & & & 2 & 2 & 3 & & & 2 & 2 \\
\hline LUL TSS & 3 & & & 2 & 1 & 2 & & & 2 & 1 \\
\hline LLL TSS & 3 & & & 2 & 1 & 3 & & & 3 & 2 \\
\hline CT subjective & Severe & & & Moderate & Moderate & Moderate & & & Moderate & $\begin{array}{l}\text { Mild-Moder- } \\
\text { ate }\end{array}$ \\
\hline \multicolumn{11}{|l|}{ Oxygen status } \\
\hline Support & $\begin{array}{l}\text { VMK } \\
40 \% \\
(10 \mathrm{~L})\end{array}$ & $\begin{array}{l}\mathrm{NC} \\
2 \mathrm{~L}\end{array}$ & $\begin{array}{l}\text { Part } \\
\text { time } \\
\mathrm{NC}\end{array}$ & None & None & $\begin{array}{l}\text { VMK40\% } \\
(10 \mathrm{~L})\end{array}$ & $\begin{array}{l}\text { VMK } \\
35 \% \\
(8 \mathrm{~L})\end{array}$ & $\begin{array}{l}\text { VMK } \\
30 \% \\
(6 \mathrm{~L})\end{array}$ & $\begin{array}{l}\text { Part time } \\
\text { NC 2L }\end{array}$ & $\begin{array}{l}\text { Patient de- } \\
\text { mand (NC } \\
2 \mathrm{~L})\end{array}$ \\
\hline Sp02 & $90 \%$ & $94 \%$ & $94 \%$ & $95 \%$ & $95-97 \%$ & $91 \%$ & $92 \%$ & $92 \%$ & $94 \%$ & $97 \%$ \\
\hline Fi02 & 272 & 327 & 350 & 400 & 432 & 268 & 270 & 330 & 337 & 395 \\
\hline \multicolumn{11}{|l|}{ COVID-19 status } \\
\hline PCR & + & & & + & & + & & & + & \\
\hline
\end{tabular}

$R T$ Radiotherapy; Normal range values: IL-6 (Interleukin-6) $<7 \mathrm{pg} / \mathrm{ml}$, D-Dimer $<0.5 \mathrm{mg} / \mathrm{l}$; Hb (Hemoglobin) males $14-18$ and females $12-16$; CRP (C-Reactive Protein) <0.500 mg/dl; Ferritin: males 22-322 ng/ml and females 10-291 ng/ml; LDH (Lactate dehydrogenase) 208-378 UI/1, Fibrinogen 200-400 mg/dl, Lymphocytes $45 \%$

$C T$ Computed Tomography, RUL Right upper lobe, $R M L$ Right middle lobe, $R L L$ Right lower lobe, $L U L$ Left upper lobe, $L L L$ Left lower lobe, TSS Total Severity Score. $1=0-25 \% ; 2=26-50 \% ; 3=51-75 \% ; 4=76-100 \%, V M K$ Venturi Mask (Ventimask), NC Nasal Cannula, $02-$ Sat Oxygen Saturation, $P C R$ Polymerase Chain reaction 


\section{Results}

\section{Clinical status}

Respiratory status improved rapidly in both patients.

Patient 1 showed an improvement on his $\mathrm{Sp02}$ and Pa02/Fi02 (>300) two days after the treatment. Supplemental oxygen with $2 \mathrm{~L} \mathrm{NC}$ was discontinued at day five, he was discharged on day eight after ULTRA-COVID with $95 \%$ Sp02 values on air, and his condition remained stable 1 and 2 months later.

Patient 2 showed a slower recovery, achieving less need of oxygen support at 2, 5 and 7 days after the treatment, intermittently requiring $2 \mathrm{~L} \mathrm{NC} 1$ month after and, dropping oxygen support two months after treatment. Pa02/Fi02 was $>300 \mathrm{~mm} \mathrm{Hg}$ at day 5 and she was discharged 14 days after ultra-LDRT.

Both patients reported improvement of symptoms such as asthenia and dyspnea after $48 \mathrm{~h}$ of treatment. In addition, the inflammatory parameters showed a decline, followed by some fluctuation and eventual stabilization. We want to highlight in particular the decrease in IL-6 (CRS). The viral status results by PCR 1 month after treatment were positive in patient 1 and negative in patient 2 .

No significant or acute adverse events were observed, even after a 2-month follow-up period.

\section{Radiological status}

ULTRA-COVID intervention showed an improvement of the TSS score in both patients after the first scan, with greater improvement in patient 1 (Table 2).

The first CT scan at 7 days in patient 1 showed fibrotic subpleural bands and bronchial and vascular retraction was also present (Fig. 1b). The second scan at 4 weeks showed fewer consolidation areas, although moderate lung involvement persisted (Fig. 1c).

Table 3 Low-dose radiotherapy trials applied to COVID-19 patients. Source: ClinicalTrials.gov [19]

\begin{tabular}{|c|c|c|}
\hline Trial & Institution/Location & Dose \\
\hline $\begin{array}{l}\text { RESCUE1- } \\
19 \\
\text { Phase } 1 \\
\text { and } 2\end{array}$ & $\begin{array}{l}\text { Emory University Hospital Midtown/Winship Cancer } \\
\text { Institute, Atlanta, GA, USA }\end{array}$ & Single fraction of whole lung low-dose radiation therapy ${ }^{a}$ \\
\hline $\begin{array}{l}\text { RESCUE1- } \\
19 \\
\text { Phase } 3\end{array}$ & $\begin{array}{l}\text { Emory University Hospital Midtown/Winship Cancer } \\
\text { Institute, Atlanta, GA, USA }\end{array}$ & Single fraction of whole lung low-dose radiation therapy ${ }^{a}$ \\
\hline COLOR-19 & $\begin{array}{l}\text { Radiation Oncology Department, ASST SpedaliCivili, } \\
\text { Brescia, Brescia, Italy }\end{array}$ & Single fraction whole lung radiotherapy of $0.7 \mathrm{~Gy}$ \\
\hline NCT04390412 & $\begin{array}{l}\text { Imam Hossein Hospital Tehran, Iran, Islamic Republic } \\
\text { of Iran }\end{array}$ & $\begin{array}{l}0.5 \mathrm{~Gy} \text { radiation to both lungs; may be another fraction of } 0.5 \mathrm{~Gy} \\
\text { (maximum } 1 \mathrm{~Gy} \text { in two fractions at least } 72 \mathrm{~h} \text { apart) }\end{array}$ \\
\hline VENTED & $\begin{array}{l}\text { Arthur G. James Cancer Hospital and Solove Research } \\
\text { Institute at Ohio State University Medical Center, } \\
\text { Columbus, OH, USA }\end{array}$ & Single dose of $0.8 \mathrm{~Gy}$ to the bilateral lungs \\
\hline NCT04466683 & $\begin{array}{l}\text { Ohio State University Comprehensive Cancer Center, } \\
\text { USA }\end{array}$ & $\begin{array}{l}\text { Low radiation arm: A single dose of } 0.35 \mathrm{~Gy} \text { to whole thorax; high } \\
\text { radiation arm: A single dose of } 1 \mathrm{~Gy} \text { to whole thorax; selection of } \\
\text { best radiotherapy dose-arm after } 20 \text { patients }\end{array}$ \\
\hline NCT04394793 & $\begin{array}{l}\text { All India Institute of Medical Sciences, New Delhi, } \\
\text { India }\end{array}$ & Single 0.7 Gy to lungs \\
\hline NCT04393948 & Brigham and Women's Hospital, Boston, MA, USA & 1 Gy single lung radiation; $1 \mathrm{cGy}$ bilateral lung radiation \\
\hline NCT04534790 & Social Secure & Radiotherapy 1 Gy to whole lung \\
\hline NCT04493294 & $\begin{array}{l}\text { Institute of Radiation Oncology, Cantonal hospital } \\
\text { Graubuenden, Chur, Switzerland }\end{array}$ & Low dose whole lung radiotherapy ${ }^{a}$ \\
\hline IPACOVID & $\begin{array}{l}\text { Hospital Sant Joan de Reus, Tarragona, Spain, Hospi- } \\
\text { tal Del Mar, Barcelona, Spain, Hospital Universitario, } \\
\text { Madrid, Sanchinarro Madrid, Spain }\end{array}$ & $\begin{array}{l}\text { Bilateral low-dose lung irradiation: } 0.5 \mathrm{~Gy} \text { in a single fraction. Op- } \\
\text { tionally, additional } 0.5 \mathrm{~Gy} \text { fraction } 48 \mathrm{~h} \text { later }\end{array}$ \\
\hline $\begin{array}{l}\text { LOWRAD- } \\
\text { Cov19 }\end{array}$ & $\begin{array}{l}\text { Servicio de Oncología Radioterápica. Hospital Clínico } \\
\text { San Carlos Madrid, Spain }\end{array}$ & Low-dose radiotherapy ${ }^{\mathrm{a}}$ \\
\hline COVRTE-19 & $\begin{array}{l}\text { Hospital Provincial de Castellon, Castellón De La } \\
\text { Plana, Castellon, Spain }\end{array}$ & Low-dose lung radiation $(0.5-1.0 \mathrm{~Gy})$ \\
\hline $\begin{array}{l}\text { ULTRA- } \\
\text { COVID }\end{array}$ & $\begin{array}{l}\text { Hospital La Milagrosa, GenesisCare, Madrid, Spain, } \\
\text { Hospital Vithas Valencia Consuelo, Valencia, Spain }\end{array}$ & $\begin{array}{l}\text { Single } 0.8 \mathrm{~Gy} \text { including both whole-lungs extended } 1 \mathrm{~cm} \text { isometric } \\
\text { in all directions }\end{array}$ \\
\hline
\end{tabular}

COVID 19 Coronavirus 19 disease

${ }^{\text {a } D o s e ~ n o t ~ s p e c i f i e d ~}$ 
The first CT scan in patient 2 showed the resolution of the pneumomediastinum, but there was fibrosis and loss of volume, with fewer consolidation areas. The second CT scan at 4 weeks showed minimum fibrosis.

In both cases, we observed an improvement from moderate to mild-moderate TSS pattern (Fig. 1e, f).

\section{Discussion}

Experimental therapies have been used since the outbreak of the COVID-19 pandemic and expert societies advocated for enrolling patients into clinical studies when possible, as no standard treatment exists so far.

In this scenario, ULTRA-COVID has followed the most up-to-date evidence based on national and international guidelines; however we are facing a constantly changing situation. Indeed, some drugs used in our study (hydroxychloroquine, lopinavir/ritonavir and azithromycin) are no longer used routinely given the results of recent studies and others have taken center stage such as remdesivir. Regarding tocilizumab [17], the only potential supportive treatment for COVID-19, the scientific community is waiting for more robust studies. In this scenario of uncertainty, the interactions bias can occur towards a beneficial or detrimental effect, although none of our patients presented side effects or clinical improvement associated with the administered pharmacotherapy.

RT is a cost-effective non-toxic treatment available in most hospitals [18]. The radiobiological basis is not well known, but literature suggests that the ultra-LDRT would modulate the overreacting immune-landscape [8-10]. The design of clinical trials to investigate RT effectiveness in COVID-19 pneumonia has been justified by the RT community and ongoing trials exist ([19]; Table 3). Despite these ongoing trials, patient recruitment is still challenging.

With the ULTRA-COVID study we wanted to analyze the anti-inflammatory effect of ultra-LDRT and its potential use to mitigate this pandemic. We support the potential activity of ultra-LDRT by presenting clinical recovery of two patients with COVID-19 pneumonia and with a poor response to standard medical therapy, who would otherwise have no other treatment than IMV, but for which they were not candidates. To our knowledge, this is the first study to demonstrate the positive outcomes of a single $0.8 \mathrm{~Gy}$ of helicoidal-RT for COVID-19 pneumonia treatment, which combined clinical, imaging and laboratory outcomes over time.

We agree that the timing of the irradiation in relation to disease progression is likely to influence treatment outcomes. However, it is still unclear what the best timing for ultra-LDRT administration is. It is important to distinguish between the dominant viral phase versus the host inflammatory-cytokines-mediated response and literature supports low-dose irradiation in the early progressive stage rather than the chronic disease stage [20]. In our study, the faster recovery and the greater radiological improvement in the case of patient 1 who presented at an earlier disease stage as opposed to patient 2, whose disease stage was advanced, suggests that the earlier we apply the ultra-LDRT in the acute inflammation host phase, the better the clinical response. This hypothesis needs to be validated through a larger clinical trial.

We argue that the ultra-LDRT target is the cytokine storm and it is important that decisions about ICU escalation are made early in the patient disease journey, so that eligible patients for ultra-LDRT are identified early [19, 20]. The optimal timing for LDRT appears to be between 7 and 12 days from onset of symptoms [3].

The use of RT could stop the progression of the disease to an advance stage; and this could help curb death rates, now $3.4 \%$ on average and higher among elderly and ICU patients [21]. The optimal dose of RT is unknown with evidence supporting $0.5-1$ Gy $[2,4,5]$. The average prescription doses of the ongoing trials are 0.35 and $1 \mathrm{~Gy}$ in a single dose and; optionally, an additional $0.5 \mathrm{~Gy}$ fraction $48 \mathrm{~h}$ later in some of them (Table 3 ).

We decided to apply $0.8 \mathrm{~Gy}$ in a single session for three main reasons: (1) available literature for pneumonia treatment supports dose $0.5-1.25$ range [6], (2) the aggressiveness of the virus encouraged us to dose escalate above $0.5 \mathrm{~Gy}$ and (3) this is the minimum effective dose of gantry rotation period of Tomotherapy devices.

The strengths of our study are our rigorous inclusion criteria and the combination of clinical, radiological and laboratory result during follow-up. We observed a better clinical than radiological response and an improvement in inflammatory blood markers, which overall constitute a success to this treatment.

Although LDRT may increase the effectiveness of antiviral immune responses, it does not decrease the viability of virus directly [20]. It could be the reason why the PCR of patient 1 was positive 4 weeks later.

The main concerns about the RT use in non-neoplasic disease is its carcinogenesis and cardiovascular toxicity risk. Regarding carcinogenesis, evidence to support this risk is scarce when low-doses are used (0.1-4/1000 to $<1 / 10,000$ ) [22-26]. Our patients were older and suffered from a life-threatening illness which makes the risk less important.

In addition, no cardiovascular event or other side effects are expected in the future due to the ultra-LDRT $(0.8 \mathrm{~Gy})$. The usual dose constraints established to avoid cardiotoxicity in a standard oncological treatment such as keeping the heart mean dose <4Gy (RTOG 1005) means that the ul- 
tra-LDRT is safe for the heart. Nevertheless, a larger study sample and a longer follow-up period is necessary.

Our main study weakness was the small number of patients recruited. This can be explained by the fact that COVID-19 pneumonia cases started to decline at the time of the study and as we were heading to summer which made patient recruitment difficult. A larger study is needed to validate our study results.

We also consider the possible lead time bias as our study weakness, due to the different disease phase in which patients were included.

Despite these limitations, the preliminary results on our first two patients suggest a good response to RT and encourage us to continue.

Researchers at Emory University have also shared the preliminary results of day 7 analysis of their phase I/II trial (RESCUE1-19). Five patients were treated with a single dose of $1.5 \mathrm{~Gy}$. They have also supported that LDRT appears to be safe without any acute toxicities noted and have shown early promise of efficacy [27].

This report highlights the importance of identifying those patients who could benefit from LDRT in order to decrease the worsening of the disease, especially in those patients who are not candidates for IMV.

Further studies could demonstrate the effectiveness of LDRT, considering it as an alternative co-treatment with pharmacotherapy (or even as a sole treatment). This could be of a great importance in countries with limited or no access to expensive drugs or ICUs and it could even become standard of care in COVID-19 management. Additionally, we support that it could have a positive therapeutic impact on other viral pneumonia epidemics in which CRS has been observed [28].

\section{Conclusion}

Preliminary clinical and radiological results suggest a potential benefit of treating SARS-CoV-2 (Severe acute respiratory syndrome due to coronavirus 2) pneumonia with ultra-LDRT during the acute inflammatory phase with a positive impact on the disease's evolution and patient recovery.

Acknowledgements We thank patients and their families involved in the study, as well as all members of workforce who participated.

\section{Compliance with ethical guidelines}

Conflict of interest E. Moreno-Olmedo, V. Suárez-Gironzini, M. Pérez, T. Filigheddu., C. Mínguez, A. Sanjuan-Sanjuan, J.A. González, D. Rivas, L. Gorospe, L. Larrea and E. López declare that they have no competing interests.
Ethical standards All procedures performed in studies involving human participants or on human tissue were in accordance with the ethical standards of the institutional and/or national research committee and with the 1975 Helsinki declaration and its later amendments or comparable ethical standards. Approved by the HM Hospitales Group Ethics Committee (CEIm) on April 21, 2020. CEIm code 20.4.1597GHM. Patients signed consent was obtained after verbal information on the procedure, objective and secondary effects of the treatment.

\section{References}

1. Cuttler JM (2020). Letter to Dr. Stephen M Hahn. March 20, 2020. https://doi.org/10.13140/RG.2.2.19071.84646

2. Dhawan G, Kapoor R, Dhawan R et al (2020) Low dose radiation therapy as a potential life saving treatment for COVID-19-induced acute respiratory distress syndrome (ARDS). Radiother Oncol 147:212-216. https://doi.org/10.1016/j.radonc.2020.05.002

3. Mehta P, McAuley DF, Brown M et al (2020) COVID-19: consider cytokine storm syndromes and immunosuppression. Lancet 395(10229): 1033-1034

4. Kirkby C, Mackenzie M (2020) Is low dose radiation therapy a potential treatment for COVID-19 pneumonia? Radiother Oncol 147:221. https://doi.org/10.1016/j.radonc.2020.04.004. Epub 2020 Apr 6. PMID: 32342871; PMCID: PMC7194710

5. Chakrabarti D, Verma M (2020) Low-dose radiotherapy for SARSCoV-2 pneumonia. Strahlenther Onkol. https://doi.org/10.1007/ s00066-020-01634-8

6. Calabrese EJ, Dhawan G (2013) How radiotherapy was historically used to treat pneumonia: could it be useful today? Yale J Biol Med 86:555-570

7. Torres Royo L, Antelo Redondo G, Arquez Pianetta M et al (2020) Low-dose radiation therapy for benign pathologies. Rep Pract Oncol Radiother 25:250-254

8. Schaue D, Jahns J, Hildebrandt G et al (2005) Radiation treatment of acute inflammation in mice. Int J Radiat Biol 81:657-667

9. Arenas M, Gil F, Gironella M et al (2008) Time course of antiinflammatory effect of low-dose radiotherapy: correlation with tgfbeta (1) expression. Radiother Oncol 86:399-406

10. Rödel F, Keilholz L, Herrmann M et al (2007) Radiobilogical mechanisms in inflammatory diseases of low-dose radiation therapy. Int J Radiat Biol 83(6):357-366

11. Charlson ME et al (1987) A new method of classifying prognostic comorbidity in longitudinal studies: development and validation. J Chron Dis 40(5):373-383

12. Huang C, Wang Y, Li X et al (2020) Clinical features of patients infected with 2019 novel coronavirus in Wuhan, China. Lancet 395(10223):497-506

13. WHO-China Joint Mission (2020) Report of the WHO-China joint mission on Coronavirus disease 2019 (COVID-19)

14. Li K, Fang Y, Li W et al (2020) CT image visual quantitative evaluation and clinical classification of coronavirus disease (COVID19). Eur Radiol. https://doi.org/10.1007/s00330-020-06817-6

15. Oken M, Creech R, Tormey D et al (1982) Toxicity and response criteria of the Eastern Cooperative Oncology Group. Am J Clin Oncol 5:649-655

16. CTCAE v5.0 - November 27, 2017: https://ctep.cancer.gov/ protocoldevelopment/electronic_applications/docs/CTCAE_v5_ Quick_Reference_5x7.pdf. Accessed 27 Nov 2017

17. Alzghari SK, Acuña VS (2020) Supportive treatment with tocilizumab for COVID-19: a systematic review. J Clin Virol 127:104380. https://doi.org/10.1016/j.jcv.2020.104380

18. Lara PC et al (2020) Low dose lung radiotherapy for COVID-19 pneumonia. The rationale for a cost-effective anti-inflammatory 
treatment. Clin Trans Radiat Oncol 23:27-29. https://doi.org/10. 1016/j.ctro.2020.04.006

19. U.S. National Library of Medicine. https://clinicaltrials.gov/. Accessed 20 Oct 2020

20. Rödel F, Arenas M, Ott OJ (2020) Low-dose radiation therapy for COVID-19 pneumopathy: what is the evidence? Strahlenther Onkol. https://doi.org/10.1007/s00066-020-01635-7

21. Grasselli G, Pesenti A, Cecconi M (2020) Critical care utilization for the COVID-19 outbreak in Lombardy, Italy: early experience and forecast during an emergency response. JAMA. https://doi.org/ 10.1001/jama.2020.4031

22. Remuzzi A, Remuzzi G (2020) COVID-19 and Italy: what next? Lancet. https://doi.org/10.1016/S0140-6736(20)30627-9

23. https://www.who.int/es/dg/speeches/detail/who-director-generals-opening-remarks-at-the-media-briefing-on-covid-19---3-march2020. Accessed 3 Mar 2020

24. Trott KR, Kamprad F (2006) Estimation of cancer risks from radiotherapy of benign diseases. Strahlenther Onkol 182:431-436
25. Mckeown SR, Hatfield P, Prestwich RJD et al (2015) Radiotherapy for benign disease; assessing the risk of radiation-induced cancer following exposure to intermidate dose radiation. Br J Radiol 88:20150405

26. Mazonakis M, Damilakis J (2017) Cancer risk after radiotherapy for benign diseases. Phys Med (42):285-291. https://doi.org/10.1016/j. ejmp.2017.01.014. Epub 2017 Feb 8. PMID: 28189418

27. Hess CB et al Low-dose whole-lung radiation for COVID-19 pneumonia: planned day-7 interim analysis of a registered clinical trial. December 126(23):5109-5113. https://doi.org/10.1101/2020.06. 03.20116988

28. Channappanavar R, Perlman S (2017) Pathogenichuman coronavirus infections: causes and consequences of cytokine storm and immunopathology. Semin Immunopathol 39:529-539. https://doi. org/10.1007/s00281-017-0629-x 